\title{
Perovskite thin films via atomic layer deposition
}

\author{
Brandon R. Sutherland, Sjoerd Hoogland, Michael M. Adachi, \\ Pongsakorn Kanjanaboos, Chris T. O. Wong, Jeffrey J. McDowell, \\ Jixian Xu, Oleksandr Voznyy, Zhijun Ning, Arjan J. Houtepen, \\ and Edward H. Sargent
}

Version Post-Print/Accepted Manuscript

Citation Sutherland, B., Hoogland, S., Adachi, M., Kanjanaboos, P., Wong, C., \& (published version) McDowell, J. et al. (2014). Perovskite Thin Films via Atomic Layer Deposition. Advanced Materials, 27(1), 53-58. http://dx.doi.org/10.1002/adma.201403965

Publisher's Statement This is the peer reviewed version of the following article: Sutherland, B., Hoogland, S., Adachi, M., Kanjanaboos, P., Wong, C., \& McDowell, J. et al. (2014). Perovskite Thin Films via Atomic Layer Deposition. Advanced Materials, 27(1), 53-58, which has been published in final form at http://dx.doi.org/10.1002/adma.201403965. This article may be used for non-commercial purposes in accordance with Wiley Terms and Conditions for Self-Archiving.

How to cite TSpace items

Always cite the published version, so the author(s) will receive recognition through services that track citation counts, e.g. Scopus. If you need to cite the page number of the TSpace version (original manuscript or accepted manuscript) because you cannot access the published version, then cite the TSpace version in addition to the published version using the permanent URI (handle) found on the record page. 
Perovskite thin films via atomic layer deposition

Brandon R. Sutherland, Sjoerd Hoogland, Michael M. Adachi, Pongsakorn Kanjanaboos, Chris T. O. Wong, Jeffrey J. McDowell, Jixian Xu, Oleksandr Voznyy, Zhijun Ning, Arjan J. Houtepen $^{\S}$, and Edward H. Sargent*

Department of Electrical and Computer Engineering, University of Toronto, 10 King's College Road, Toronto, Ontario, M5S 3G4, Canada

$\S$ Department of Chemical Engineering, Delft University of Technology, Julianalaan 136, 2628 BL Delft, The Netherlands

E-mail: ted.sargent@utoronto.ca

Keywords: perovskites, atomic layer deposition, optical gain, transient absorption

Lead iodide perovskites are an attractive material for thin film optoelectronic devices due to their facile methods of fabrication, high absorption per unit length, and remarkable efficiency in charge carrier transport. We report the fabrication of $\mathrm{CH}_{3} \mathrm{NH}_{3} \mathrm{PbI}_{3}$ perovskite thin films via a new materials processing route-perovskite atomic layer deposition (ALD). The new process, which relies on a place-exchangedbased conversion of $\mathrm{ALD} \mathrm{PbS}$ to $\mathrm{PbI}_{2}$, generates films having material properties comparable to the best previously-reported $\mathrm{CH}_{3} \mathrm{NH}_{3} \mathrm{PbI}_{3}$ perovskite thin films. We examine the remarkable properties of this material, elucidating the optical gain dynamics using ultrafast pump-probe spectroscopy. We obtain a net optical gain coefficient of $3200 \pm 830 \mathrm{~cm}^{-1}$, an impressive number for a polycrystalline material and indeed comparable to material gain in the best single-crystal semiconductors used in lasing and optical amplification.

Deposited via facile fabrication methods from the solution or gas phase, $\mathrm{CH}_{3} \mathrm{NH}_{3} \mathrm{PbI}_{3}$ is a direct-bandgap semiconductor with exceptional optoelectronic material properties. ${ }^{[1]}$ It combines an optical bandgap in the near-infrared at $1.55 \mathrm{eV},{ }^{[2]}$ a remarkably high absorption 
per unit length exceeding $10^{4} \mathrm{~cm}^{-1}$ just above the bandedge, ${ }^{[3,4]}$ and charge carrier diffusion lengths up to and exceeding $1 \mu \mathrm{m} . .^{[4,5]}$ The latter attests to a bandgap substantially free of charge-trapping defect states that are otherwise normally present in materials deposited under non-epitaxial growth conditions. ${ }^{[2]}$

Lead organohalide perovskites $-\mathrm{CH}_{3} \mathrm{NH}_{3} \mathrm{PbI}_{3}$ and mixed-halide derivatives - have enabled great strides towards low-cost, high-efficiency photovoltaic cells, surging from solar cell power conversion efficiencies of $6.5 \%$, to a certified $17.9 \%$ all in the short span of three years (Aug 2011 - May 2014). ${ }^{[1-3,6-11]}$ The impressive physical properties of this material have further been leveraged towards radiative devices: light-emitting diodes, ${ }^{[12]}$ and lasers. ${ }^{[13-15]}$ Perovskites are of increasing interest in light-emissive technology by virtue of their spectral tunability, ${ }^{[15]}$ high photoluminescence yield, ${ }^{[13]}$ long photogenerated carrier lifetimes, ${ }^{[13]}$ and ambipolar charge transport. ${ }^{[4]}$

Lead-iodide perovskites are typically fabricated using one of three methods: 1) sequential deposition of solution processed $\mathrm{PbI}_{2}$ followed by a solution ${ }^{[1]}$ or gas phase ${ }^{[16]}$ exposure to $\mathrm{CH}_{3} \mathrm{NH}_{3} \mathrm{I}$, 2) directly from a lead-halide perovskite precursor solution, ${ }^{[2]}$ or 3) through simultaneous co-evaporation of a lead-halide salt and $\mathrm{CH}_{3} \mathrm{NH}_{3} \mathrm{I}^{\left[{ }^{[9]}\right.}$ These fabrication strategies have led to solid state thin films of high purity and crystallinity, resulting in a new class of efficient optoelectronic devices utilizing perovskites as an active medium.

Here we pursued a perovskite fabrication strategy that would leverage atomic layer deposition (ALD), a low-vacuum and low-temperature deposition technique with a wide process window capable of uniform, conformal growth of films over large areas with atomic thickness precision. Attractively, it is a proven technology, now adopted in the electronics industry in semiconductor manufacturing. Further, ALD has demonstrated viability in high-throughput, roll-to-roll compatible processes, indicating its potential in manufacturing scale-up. ${ }^{[17]}$ 
Presently, there are no processes for the growth of halide compounds via ALD. Therefore, neither the direct growth of $\mathrm{CH}_{3} \mathrm{NH}_{3} \mathrm{PbI}_{3}$ nor of $\mathrm{PbI}_{2}$ for subsequent conversion to $\mathrm{CH}_{3} \mathrm{NH}_{3} \mathrm{PbI}_{3}$, is available. To overcome this, we sought to deposit a seed layer to the formation of $\mathrm{PbI}_{2}$ which could then be converted to $\mathrm{CH}_{3} \mathrm{NH}_{3} \mathrm{PbI}_{3}$ thin films. Possible candidates with known ALD-enabled processes are $\mathrm{PbO}$ and $\mathrm{PbS}$. We chose to pursue $\mathrm{PbS}$ since it has a lower bond dissociation energy $\left(\mathrm{D}^{\circ} \mathrm{PbS}=3.3 \mathrm{eV}, \mathrm{D}^{\circ} \mathrm{PbO}=4.1 \mathrm{eV}\right)^{[18]}$ and is thus more likely to react completely with reagents in subsequent processing. Atomic layer deposition of lead sulfide has yielded thin films with controlled thickness, high purity, and distinct crystallographic orientations. ${ }^{[19-21]}$

A chief benefit of ALD is its compatibility with a broad range of substrates by reason of strong adhesion under normal processing conditions. We chose glass due to its wide availability, its electrically insulating character, and its low refractive index, enabling relevant studies on the optical gain dynamics of the film. Figure 1 details the perovskite ALD process. We begin with atomic layer deposition of a seed film of lead sulfide from controlled alternating pulses of $\mathrm{H}_{2} \mathrm{~S}$ and $\mathrm{Pb}$ (tmhd) $)_{2} \mathrm{ALD}$ precursors. The glass substrate has been treated with $\mathrm{O}_{2}$ plasma immediately prior to deposition for final cleaning and enhanced reactivity with $\mathrm{H}_{2} \mathrm{~S}$ due to increased hydroxyl surface passivation. Layers of $\mathrm{PbS}$ are grown with each cycle at a measured growth rate of $1.3 \AA$ / cycle, $\sim 0.2$ monolayers / cycle, consistent with prior reports. ${ }^{[19]}$ Once the desired thickness of $\mathrm{PbS}$ has been grown, the entire film is then converted to $\mathrm{PbI}_{2}$ through exposure to iodine gas generated by subliming solid iodine in a closed system. The $\mathrm{PbI}_{2}$ is then converted to $\mathrm{CH}_{3} \mathrm{NH}_{3} \mathrm{PbI}_{3}\left(\mathrm{MAPbI}_{3}\right)$ through a $60 \mathrm{~s}$ dip in methylammonium iodide (MAI) in IPA. This process is summarized in Figure 1a. Atomic force microscopy (AFM) is used to measure the grain-size (D) and arithmetic mean roughness $\left(\mathrm{R}_{\mathrm{a}}\right)$ of $\mathrm{PbS}, \mathrm{PbI}_{2}$, and $\mathrm{MAPbI}_{3}$, as detailed in Figure 1b. All three films form polycrystalline domains with $\mathrm{R}_{\mathrm{a}}$ and $\mathrm{D}$ values, respectively: $\mathrm{PbS}[1.8 \mathrm{~nm}, 30 \pm 5 \mathrm{~nm}], \mathrm{PbI}_{2}[1.1 \mathrm{~nm}, 51 \pm 8$ 
$\mathrm{nm}]$, and $\mathrm{MAPbI}_{3}[18.7 \mathrm{~nm}, 140 \pm 80 \mathrm{~nm}]$. The final $\mathrm{MAPbI}_{3}$ perovskite film morphology is thus governed by the MAI treatment. Insets show images of the films at each stage on a glass substrate after 330 cycles of ALD PbS $(\sim 43 \mathrm{~nm})$. The thicknesses of the $\mathrm{PbI}_{2}$ and $\mathrm{MAPbI}_{3}$ films were measured to be $40 \mathrm{~nm}$ and $75 \mathrm{~nm}$ respectively. The film thicknesses at each stage are consistent with variations in the crystal lattice parameters of PbS ( $\mathrm{a}=\mathrm{c}=5.936 \AA$, JCPDS 02-0699), $\mathrm{PbI}_{2}\left(\mathrm{a}=4.557, \mathrm{c}=6.979 \AA\right.$, JCPDS 07-0235), and $\mathrm{CH}_{3} \mathrm{NH}_{3} \mathrm{PbI}_{3}(\mathrm{a}=8.78 \AA, \mathrm{c}=$ 12.70 A, ref ${ }^{[22]}$ ). Assuming random crystal orientations across a lateral micron-scale (over which thickness is sampled via profilometry), the average lattice constants are: PbS: $5.936 \AA$, $\mathrm{PbI}_{2}$ : $5.768 \AA$, and $\mathrm{CH}_{3} \mathrm{NH}_{3} \mathrm{PbI}_{3}: 10.74 \AA$. For each film, the ratio of the averaged lattice constant, $\mathrm{a}_{\mathrm{avg}}$, to film thickness, $\mathrm{d}$, are in excellent agreement, supporting the expectation of a complete place-exchange. $\mathrm{a}_{\mathrm{avg}} / \mathrm{d}$ for $\mathrm{PbS}, \mathrm{PbI}_{2}, \mathrm{CH}_{3} \mathrm{NH}_{3} \mathrm{PbI}_{3}$ respectively: $72.4 \pm 3.03,69.3 \pm$ 1.91, and $69.8 \pm 17.4$. The increase in uncertainty for ratios with $\mathrm{MAPbI}_{3}$ is a result of the increased surface roughness of those films.

In Figure 2 we examine the spectroscopic properties of the thin films in the perovskite ALD process to confirm their chemical makeup, confirm complete stepwise conversion, and assess their phase purity. X-ray photoelectron spectroscopy confirms the elemental presence of $\mathrm{Pb}, \mathrm{I}$, $\mathrm{S}$, and $\mathrm{N}$ in each of the expected films: $\mathrm{PbS}, \mathrm{PbI}_{2}$, and $\mathrm{MAPbI}_{3}$ (Figure 2a).

Through a complementary $\mathrm{x}$-ray diffraction analysis, we further confirmed the material composition at each step and demonstrated that the conversion processes of $\mathrm{PbS}$ to $\mathrm{PbI}_{2}$, and $\mathrm{PbI}_{2}$ to $\mathrm{MAPbI}_{3}$, is complete, with no signatures of prior crystalline phases in subsequent films. Figure $2 b$ correlates the measured XRD spectrum for the films at each step of the conversion process to the literature standards for $\mathrm{PbS}$ (JCPDS 02-0699), $\mathrm{PbI}_{2}$ (JCPDS 070235), and $\mathrm{MAPbI}_{3}$ (ref. ${ }^{[1,9,10,23]}$ ). ALD PbS shows one dominant (200) phase, and one secondary (400) peak (Figure $2 \mathrm{~b}$, bottom). After $\mathrm{I}_{2}$ gas exposure, these peaks are no longer present, and characteristic hematite $\mathrm{PbI}_{2}$ (001), (101), (003), and (004) signatures emerge. 
Following the treatment with MAI all previous peaks are absent and characteristic $\mathrm{MAPbI}_{3}$ signatures appear: dominant (110) and (220) peaks, with a smaller (202) peak, and residual signatures of (312), (224), and (314). This confirms that the materials at each step of the perovskite ALD process are as designed and that the stepwise conversion produces a complete place-exchange.

A 45 degree scanning electron microscope image shows the polycrystalline grains on the surface of the fabricated $\mathrm{MAPbI}_{3}$ films (Figure 3a). The spectral absorption coefficient, $\alpha(\mathrm{E})$ is shown in Figure $3 b$. The fabricated perovskite thin films have an absorption onset at 1.55 $\mathrm{eV}$, with $\alpha$ exceeding $1.75 \times 10^{4} \mathrm{~cm}^{-1}$ at the absorption knee at $1.66 \mathrm{eV}$, comparable to values reported in high-performance photovoltaic $\mathrm{MAPbI}_{3}$ active layers. ${ }^{[4,11]}$ The temperature dependent photoluminescence (PL) is shown in Figure 3c. The room-temperature PL is centered at $1.63 \mathrm{eV}$, and decreases with decreasing temperature. A phase change from tetragonal to orthorhombic occurs between 150 and $125 \mathrm{~K}$, after which the bandgaptemperature coefficient also changes from positive to negative, consistent with prior reports. $^{[24]}$

To elucidate gain dynamics, we studied the transient evolution of the film absorption using ultrafast pump-probe spectroscopy. We excited our sample with an optical pump of energy $2.70 \mathrm{eV}$, with $180 \mathrm{fs}$ pulses at a repetition rate of $2.5 \mathrm{kHz}$, and probed the absorption with a white light source spanning $1.38-2.75 \mathrm{eV}$.

A representative 2D map of the transient absorption spectrum is shown in Figure 3a. Here, the change in absorbance $\Delta \mathrm{A}$ is shown as a color height-map as a function of wavelength and delay time. The excitation fluence was $4.5 \mu \mathrm{J} \mathrm{cm}$. Broad photoinduced absorption is observed between 500 and $700 \mathrm{~nm}$. A short-lived derivative-like feature near the optical bandgap (see blue-red transition $750-790 \mathrm{~nm}$ in the first $\sim$ picosecond) indicates an excitation-induced red-shift of the bandgap during the first few hundred femtoseconds. The 
most prominent feature is a strong absorption bleach near the bandgap that results from statefilling. For this relatively low fluence the absorption bleach is long-lived.

To investigate material gain we focus on the total absorbance $\mathrm{A}(\mathrm{E}, \mathrm{t})=\Delta \mathrm{A}(\mathrm{E}, \mathrm{t})+\mathrm{A}_{0}(\mathrm{E})$, where $\mathrm{A}_{0}(\mathrm{E})$ is the linear absorption spectrum. Material gain is achieved when a negative total absorbance is observed. Figure $3 b$ shows total absorption spectra at various pump-probe delay times obtained at a pump fluence of $70 \mu \mathrm{J} \mathrm{cm}^{-2}$. Gain is observed between approximately 1.5

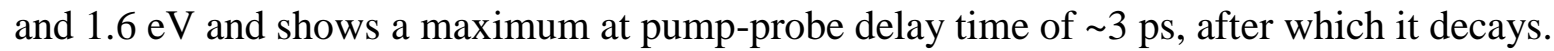

To assess the spectral position of the maximum gain as a function of fluence, we show (Figure 3c) the total absorption spectrum at a 3 ps time delay for various excitation fluences. Figure $3 \mathrm{~d}$ shows the time evolution of the absorbance plotted at the dotted line in Figure $3 \mathrm{c}$ at 1.58 $\mathrm{eV}$, a photon energy just above the gain maximum. At fluences well above the gain threshold

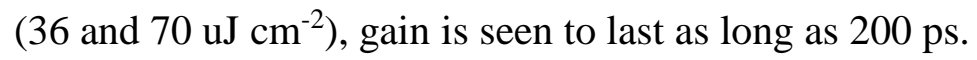

At the lowest fluence, the decay of the absorption back to the linear absorption level is welldescribed by a single exponential with a 2 ns lifetime, in line with photoluminescence lifetimes previously published for lead-iodide perovskites. ${ }^{[13]}$ At higher fluences, the decay becomes increasingly rapid, indicative of higher-order recombination.

The inset in Figure $3 \mathrm{~d}$ shows the minimum absorbance value (i.e. maximum gain) as a function of fluence, together with a $3^{\text {rd }}$ order polynomial fit as a guide for the eye. A gain threshold of approximately $16 \mu \mathrm{J} \mathrm{cm}^{-2}$ is obtained. The maximum observed gain has a value of $10 \mathrm{mOD}$, together with the measured film thickness of this sample of $72 \mathrm{~nm}$, this corresponds to a gain coefficient of $3200 \pm 830 \mathrm{~cm}^{-1}$. This value is comparable to singlecrystal semiconductors used in commercial optical amplification technology. ${ }^{[25]}$ This is, once again, a testament to the well-defined band edges of the perovskite film, despite the fact that it is a polycrystalline material. 
Organometallic perovskite ALD is a versatile process for the deposition of perovskite thin films possessing exceptional materials quality for applications in next-generation optoelectronics. In particular, the impressive optical gain coefficient further highlights the potential for perovskites broadly in semiconductor-optical amplifiers and lasers. Utilizing perovskite ALD, facile integration of perovskites into a CMOS defined optical framework containing rib-waveguides and on-chip cavities such as elliptical and spherical resonators can be achieved. Atomic layer deposition for low-temperature, conformal, large-area growth of perovskites across a wide process-window offers promise in light emission and beyond.

\section{Experimental Section}

ALD perovskite sample fabrication. Glass substrates were prepared by first sonicating in acetone, then isopropyl alcohol, and then deionized water, each for 15 minutes. Samples were exposed to a 10 minute 100 mTorr oxygen plasma treatment immediately prior to atomic layer deposition.

$\mathrm{CH}_{3} \mathrm{NH}_{3} \mathrm{PbI}_{3}$ perovskite films have been fabricated on these substrates by a three-step method. A) PbS deposition: Cleaned glass slides are placed into a Cambridge Savannah S100 atomic layer deposition system with the sample chamber held at $150{ }^{\circ} \mathrm{C}$ and $1 \mathrm{mTorr}$ base pressure (with no inlet flow). Alternating pulses of $\mathrm{Pb}(\mathrm{tmhd})_{2}$ and $\mathrm{H}_{2} \mathrm{~S}$ precursors (0.5 s pulse duration for both) build up the PbS film of a desired thickness. The purge time between precursor pulses was $20 \mathrm{~s}$, and a nitrogen carrier gas was used at a volumetric flow rate of $10 \mathrm{sccm}$. B) $\mathrm{PbI}_{2}$ conversion: $100 \mathrm{mg}$ of iodine chips are placed into a $250 \mathrm{~mL}$ container which contains the ALD PbS films. The container is sealed and heated on a $120^{\circ} \mathrm{C}$ hotplate for 16 hours. After treatment, the samples are completely yellow and have been converted to $\mathrm{PbI}_{2} . \mathrm{C}$ ) MAPbI 3 conversion: The $\mathrm{PbI}_{2}$ films are dipped into a $30 \mathrm{mg} / \mathrm{mL}$ solution of $\mathrm{CH}_{3} \mathrm{NH}_{3} \mathrm{I}$ 
dissolved in isopropyl alcohol (IPA) for $60 \mathrm{~s}$, immediately dipped into IPA for another $60 \mathrm{~s}$, and then dried on a hot plate at $70{ }^{\circ} \mathrm{C}$ for 30 minutes.

Atomic force microscopy (AFM). AFM measurements were performed using PeakForce Tapping and PeakForce Quantitative Nanomechanical Property Mapping on Bruker Catalyst. Fast force curves were performed as the AFM scanned the samples' surfaces. Prior to measurement, the cantilever tip's radius and reflection sensitivity were measured via imaging on a rough surface and a force curve measurement on a quartz standard. In addition, the spring constant was measured via thermal vibration measurement. Sharp cantilevers with tip radius smaller than $10 \mathrm{~nm}$ were used.

X-ray photoelectron spectroscopy. A PHI-5500 XPS system was used to confirm the incorporation of $\mathrm{Pb}, \mathrm{I}, \mathrm{S}$, and $\mathrm{N}$ in $\mathrm{PbS}, \mathrm{PbI}_{2}$, and $\mathrm{CH}_{3} \mathrm{NH}_{3} \mathrm{PbI}_{3}$. A monochromated $\mathrm{Al} \mathrm{K} \alpha$ radiation source $(1486.7 \mathrm{eV})$ was used to excite photoelectrons under ultrahigh vacuum $\left(10^{-9}\right.$ Torr).

$X$-ray diffraction. Phase purity was confirmed by powder XRD patterns collected with a Rigaku Miniflex diffractometer equipped with a $\mathrm{Cu} \mathrm{K \alpha}$ X-ray tube operated at $40 \mathrm{kV}$ and 15 $\mathrm{mA}$ with a time per step of 3 s. Samples were rotated during data collection. Under these conditions, the intensity of the strongest reflection was approximately 1000 counts.

Scanning electron microscopy (SEM). A FEI Quanta FEG 250 environmental-SEM at an accelerating voltage of $10 \mathrm{kV}$, a working distance of $10 \mathrm{~mm}$, and a pressure of $6.3 \times 10^{-4} \mathrm{~Pa}$ was used sample imaging. 
Absorption coefficient. The optical density, AOD, of the perovskite film was measured with a Perkin Elmer Lambda 950 spectrophotometer with an integrating sphere. A DekTak 3 profilometer was used to measure the film thickness, d. This was used to calculate the absorption coefficient, $\alpha=\log _{10}(\mathrm{e}) \cdot \mathrm{A}_{\mathrm{OD}} / \mathrm{d}$. Uncertainty was estimated from the measured surface roughness of the film.

Photoluminescence. Perovskite samples were excited with a frequency-tripled Nd:YAG 355 $\mathrm{nm}$ laser with a pulse duration of $2 \mathrm{~ns}$ and a repetition rate of $100 \mathrm{~Hz}$. Photoluminscence was collected with an Ocean Optics USB 2000+ spectrometer. Samples were cooled to cryogenic temperatures using a home-built liquid nitrogen cryostat.

Ultrafast pump-probe spectroscopy. A Light Conversion Pharos laser with an optical parametric amplifier (Orpheus, Lightconversion) and a Helios white-light transient absorption spectrometer from Ultrafast Systems were used for pump-probe measurements. The pump beam was a $460 \mathrm{~nm}$ laser source with $180 \mathrm{fs}$ pulse duration and $2.5 \mathrm{kHz}$ repetition rate. Transient absorption spectra in the visible $(450-900 \mathrm{~nm})$ were recorded with an Ultrafast Systems HELIOS spectrometer at a repetition rate of $5000 \mathrm{~Hz}$ using broadband probe pulses generated in a sapphire crystal pumped by the $1030 \mathrm{~nm}$ fundamental of the laser. The sample was held in an air-tight $\mathrm{N}_{2}$ filled cell. To correct for chirp on the probe pulse a bare glass substrate was measured. The time-zero was determined for each wavelength based on the coherent artifact. We subtracted a third-order polynomial fit to this coherent artifact from the raw data to obtain the chirp-corrected image shown in Figure 3a. 


\section{Acknowledgements}

This publication is based in part on work supported by an award (KUS-11-009-21) from the King Abdullah University of Science and Technology (KAUST), by the Ontario Research Fund Research Excellence Program and by the Natural Sciences and Engineering Research Council (NSERC) of Canada. The authors thank Cambridge Nanotech, Fritz Prinz, and Orlando Trejo for their advice on ALD PbS film fabrication. The authors thank L.T. Kunneman for his assistance in the data analysis of the transient absorption measurements. The authors also thank M. Yuan, H. Dong, R. Wolowiec, and D. Kopilovic for their help during the course of the study.

Received: ((will be filled in by the editorial staff))

Revised: ((will be filled in by the editorial staff)) Published online: ((will be filled in by the editorial staff)) 
[1] J. Burschka, N. Pellet, S.-J. Moon, R. Humphry-Baker, P. Gao, M. K. Nazeeruddin, M. Grätzel, Nature 2013, 499, 316.

[2] M. M. Lee, J. Teuscher, T. Miyasaka, T. N. Murakami, H. J. Snaith, Science 2012, 338, 643.

[3] H.-S. Kim, C.-R. Lee, J.-H. Im, K.-B. Lee, T. Moehl, A. Marchioro, S.-J. Moon, R. Humphry-Baker, J.-H. Yum, J. E. Moser, M. Grätzel, N.-G. Park, Sci. Rep. 2012, 2, DOI 10.1038/srep00591.

[4] G. Xing, N. Mathews, S. Sun, S. S. Lim, Y. M. Lam, M. Gratzel, S. Mhaisalkar, T. C. Sum, Science 2013, 342, 344.

[5] S. D. Stranks, G. E. Eperon, G. Grancini, C. Menelaou, M. J. P. Alcocer, T. Leijtens, L. M. Herz, A. Petrozza, H. J. Snaith, Science 2013, 342, 341.

[6] J.-H. Im, C.-R. Lee, J.-W. Lee, S.-W. Park, N.-G. Park, Nanoscale 2011, 3, 4088.

[7] J. H. Noh, S. H. Im, J. H. Heo, T. N. Mandal, S. I. Seok, Nano Lett. 2013, 13, 1764.

[8] J. H. Heo, S. H. Im, J. H. Noh, T. N. Mandal, C.-S. Lim, J. A. Chang, Y. H. Lee, H. Kim, A. Sarkar, M. K. Nazeeruddin, M. Grätzel, S. I. Seok, Nat. Photonics 2013, 7, 486.

[9] M. Liu, M. B. Johnston, H. J. Snaith, Nature 2013, 501, 395.

[10] N. J. Jeon, J. H. Noh, Y. C. Kim, W. S. Yang, S. Ryu, S. I. Seok, Nat. Mater. 2014, 13, 897.

[11] M. A. Green, A. Ho-Baillie, H. J. Snaith, Nat. Photonics 2014, 8, 506.

[12] Z.-K. Tan, R. S. Moghaddam, M. L. Lai, P. Docampo, R. Higler, F. Deschler, M. Price, A. Sadhanala, L. M. Pazos, D. Credgington, F. Hanusch, T. Bein, H. J. Snaith, R. H. Friend, Nat. Nanotechnol. 2014, DOI 10.1038/nnano.2014.149.

[13] F. Deschler, M. Price, S. Pathak, L. E. Klintberg, D.-D. Jarausch, R. Higler, S. Hüttner, T. Leijtens, S. D. Stranks, H. J. Snaith, M. Atatüre, R. T. Phillips, R. H. Friend, J. Phys. Chem. Lett. 2014, 5, 1421.

[14] Q. Zhang, S. T. Ha, X. Liu, T. C. Sum, Q. Xiong, Nano Lett. 2014, 140814093749002.

[15] G. Xing, N. Mathews, S. S. Lim, N. Yantara, X. Liu, D. Sabba, M. Grätzel, S. Mhaisalkar, T. C. Sum, Nat. Mater. 2014, 13, 476.

[16] Q. Chen, H. Zhou, Z. Hong, S. Luo, H.-S. Duan, H.-H. Wang, Y. Liu, G. Li, Y. Yang, J. Am. Chem. Soc. 2014, 136, 622.

[17] P. Poodt, V. Tiba, F. Werner, J. Schmidt, A. Vermeer, F. Roozeboom, J. Electrochem. Soc. 2011, 158, H937.

[18] K. Krane, Modern Physics, Wiley, 2012.

[19] N. P. Dasgupta, S. P. Walch, F. Prinz, ECS, 2008, pp. 29-36.

[20] N. P. Dasgupta, W. Lee, F. B. Prinz, Chem. Mater. 2009, 21, 3973. 
[21] N. P. Dasgupta, H. J. Jung, O. Trejo, M. T. McDowell, A. Hryciw, M. Brongersma, R. Sinclair, F. B. Prinz, Nano Lett. 2011, 11, 934.

[22] P. Umari, E. Mosconi, F. De Angelis, Sci. Rep. 2014, 4, DOI 10.1038/srep04467.

[23] Z. Chen, H. Li, Y. Tang, X. Huang, D. Ho, C.-S. Lee, Mater. Res. Express 2014, 1, 015034.

[24] Y. Yamada, T. Nakamura, M. Endo, A. Wakamiya, Y. Kanemitsu, Appl. Phys. Express 2014, 7, 032302.

[25] M. Fermann, A. Galvanauskas, G. Sucha, Ultrafast Lasers: Technology and Applications, CRC Press, 2002. 
$\mathbf{a}$
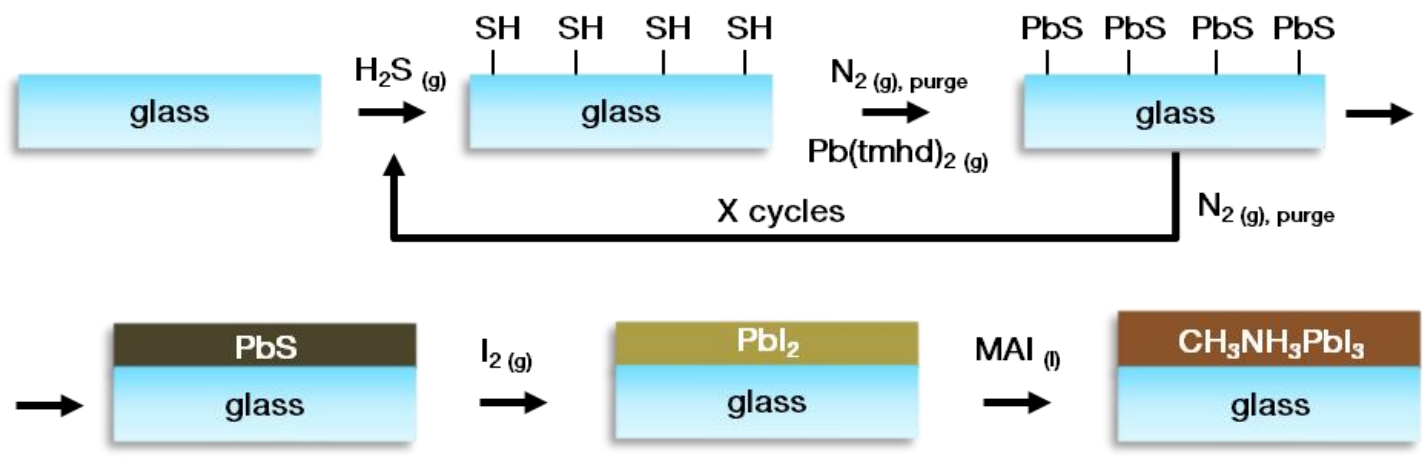

b

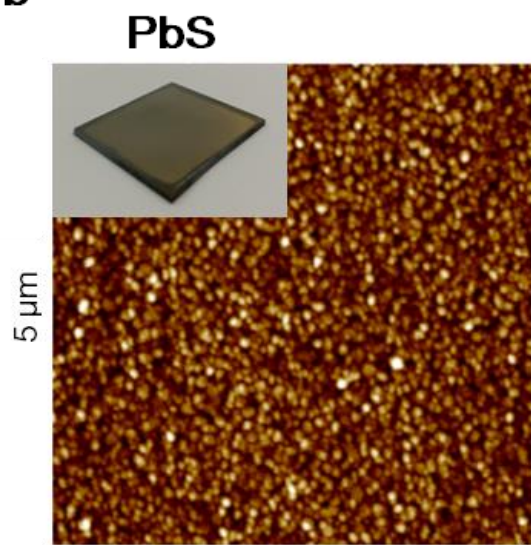

$R_{a}=1.8, D=30 \pm 5(n m)$
$\mathrm{Pbl}_{2}$

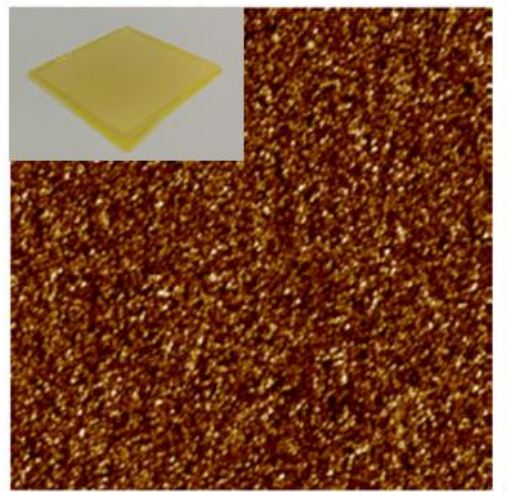

$R_{a}=1.1, D=51 \pm 8(n m)$
$\mathrm{MAPbl}_{3}$

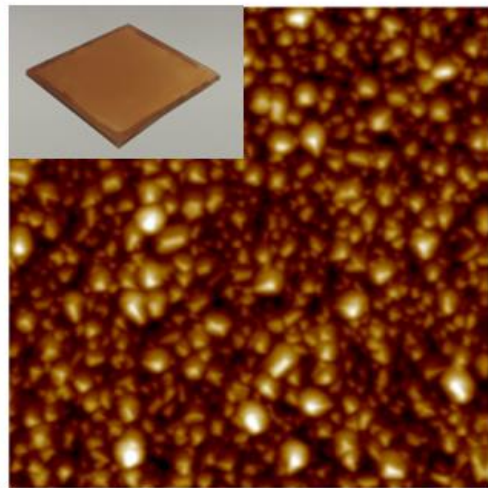

$R_{a}=18.7, D=140 \pm 80(n m)$

Figure 1. Perovskite ALD. a) Atomic layer deposition of $\mathrm{CH}_{3} \mathrm{NH}_{3} \mathrm{PbI}_{3}$. ALD PbS is deposited from alternating cycles of $\mathrm{H}_{2} \mathrm{~S}$ and $\mathrm{Pb}$ (tmhd) $)_{2}$ vapor on a glass substrate. The $\mathrm{PbS}$ sample is sealed in a nitrogen-atmosphere closed system with iodine chips sublimated at $120{ }^{\circ} \mathrm{C}$ to generate $\mathrm{I}_{2}(\mathrm{~g})$, converting the film to $\mathrm{PbI}_{2}$. The $\mathrm{PbI}_{2}$ films are dipped in $\mathrm{CH}_{3} \mathrm{NH}_{3} \mathrm{I}$ in IPA, resulting in full conversion to $\mathrm{MAPbI}_{3}$. d) Atomic force microscopy study. 5 x $5 \mu \mathrm{m}$ windows are scanned to study the surface topology development during material processing. The arithmetic mean roughness, $\mathrm{R}_{\mathrm{a}}$, and the mean grain size, $\mathrm{D}$, is shown below each image.

a

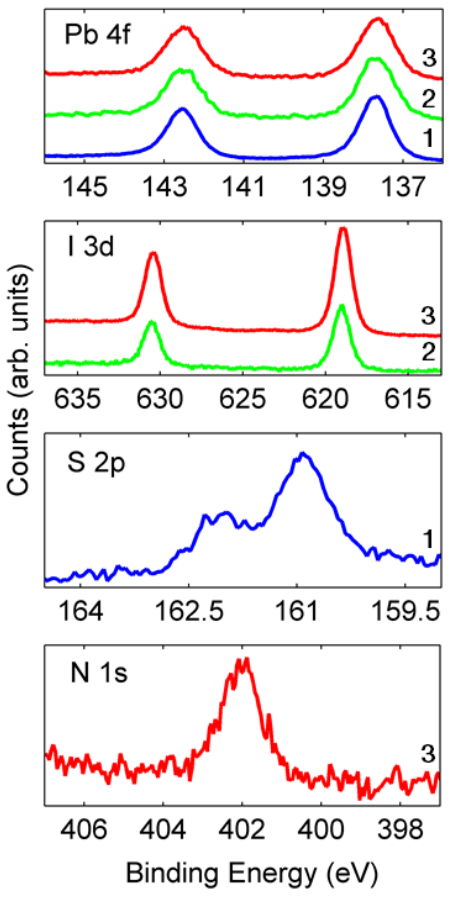

b

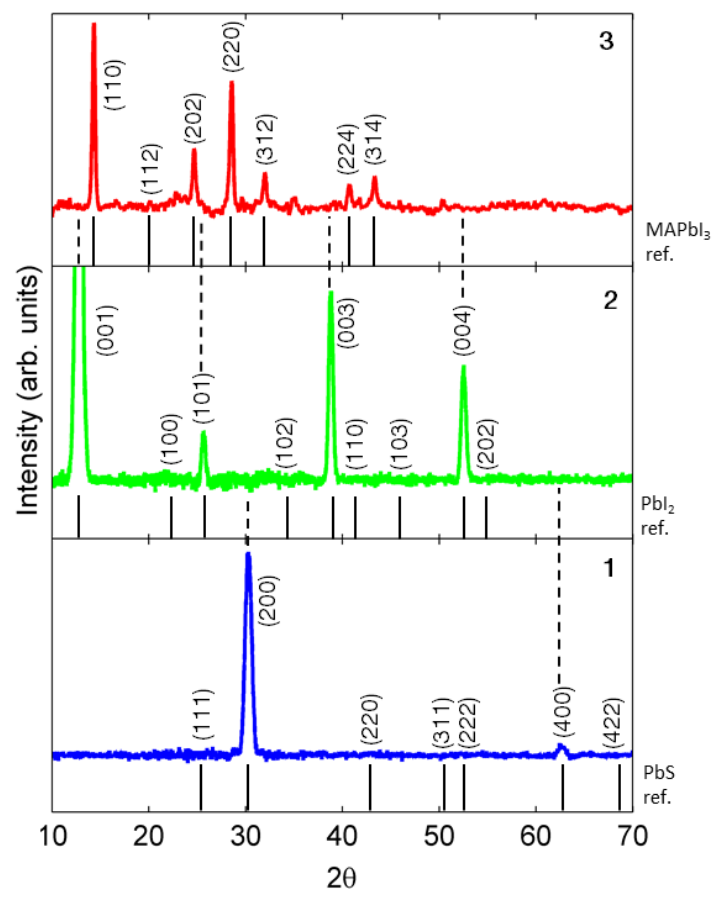

legend: $\quad$ ALD PbS 
Figure 2. Material spectroscopy on the ALD perovskite process. a) X-ray photoelectron spectroscopic analysis. Pb4f signatures are observed in all films, I3d is present in $\mathrm{PbI}_{2}$ and $\mathrm{MAPbI}_{3}, \mathrm{~S} 2 \mathrm{p}$ is present in $\mathrm{PbS}$, and N1s is present in $\mathrm{MAPbI}_{3}$. b) X-ray diffraction analysis. The presence of expected crystallographic planes relative to the material references confirms the material at each stage of the ALD perovskite process. Further, no prior crystal phases are present in subsequent films after processing from $\mathrm{PbS}$ to $\mathrm{PbI}_{2}$ to $\mathrm{MAPbI}_{3}$.

a

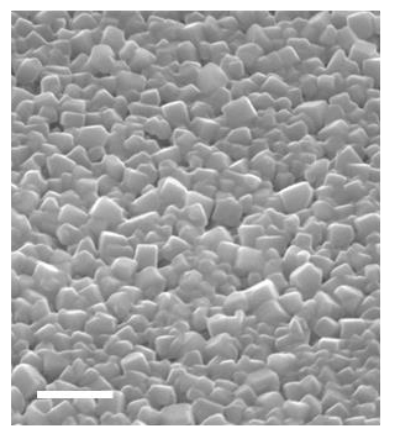

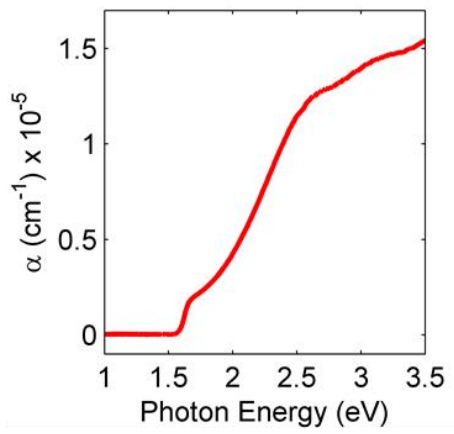

C

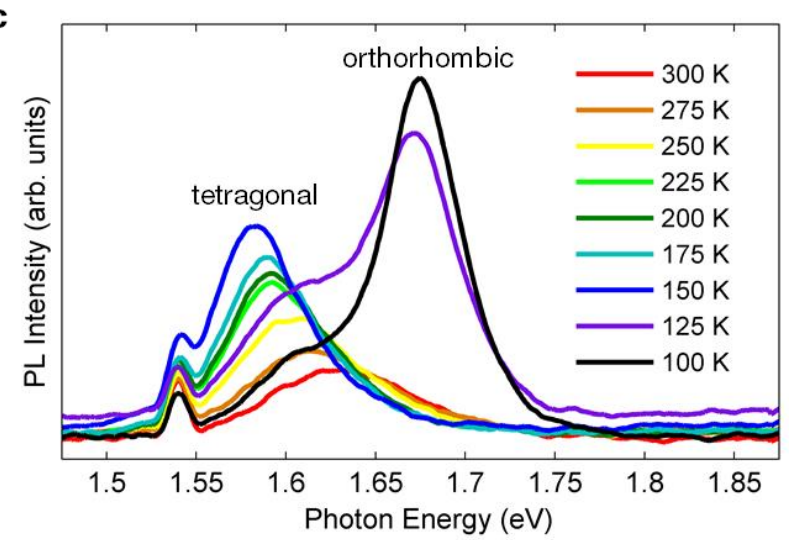

Figure 3. SEM, absorption, and photoluminscence of ALD perovskite thin films. a) a 45degree SEM image of an ALD perovskite film. b) Absorption coefficient, $\alpha$, of ALD perovskite films. The absorption onset is at $1.55 \mathrm{eV}$ and $\alpha$ exceeds $10^{-4} \mathrm{~cm}^{-1}$ at the absorption knee at $1.66 \mathrm{eV}$, indicative of a strongly-absorbing, high-quality perovskite film. c) Temperature dependent photoluminescence shows a dominantly tetragonal room-temperature phase with a phase transition to orthorhombic between 150 and $125 \mathrm{~K}$. The spectral feature at $1.54 \mathrm{eV}$ is a unfiltered harmonic of the pump laser. 

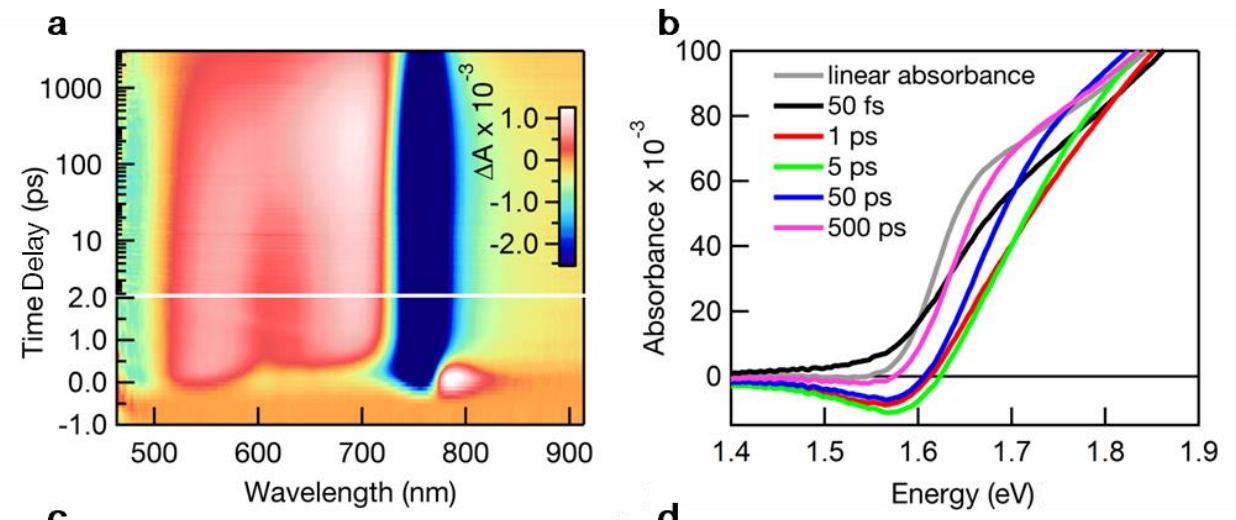

Figure

4.
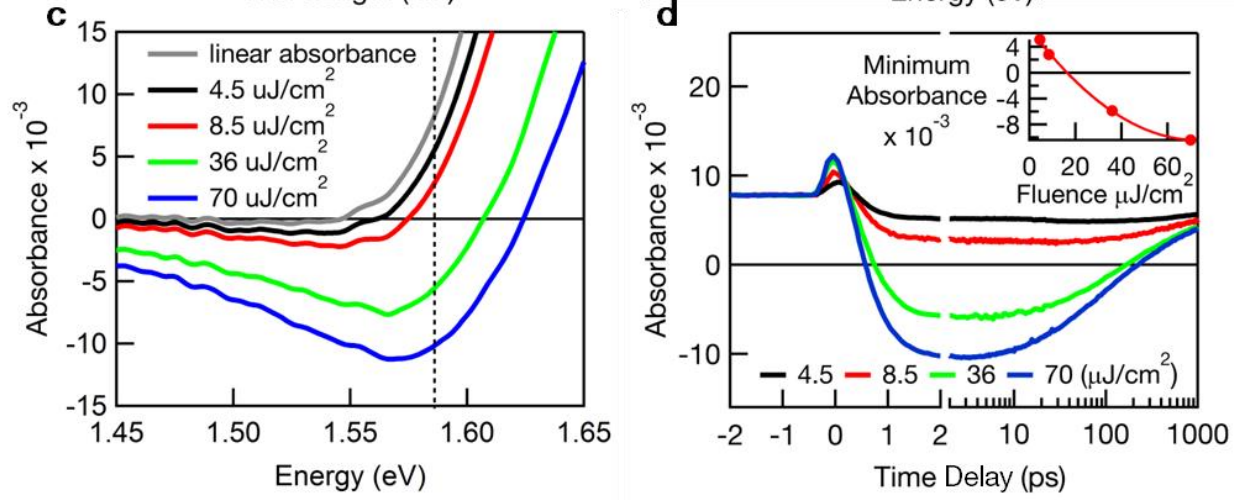

Ultrafast

transient

absorption

measurements on

ALD perovskites.

a) 2D transient absorption image displaying the

change

absorption

(color-map) vs.

wavelength and

time delay. The measurement

was obtained

with $460 \mathrm{~nm}$

pump pulses at a fluence of $4.5 \mu \mathrm{J}$

$\mathrm{cm}^{-2}$. b) Non-linear absorption spectra obtained at a fluence of $70 \mu \mathrm{J} \mathrm{cm}^{-2}$. Gain (negative absorbance) appears after $500 \mathrm{fs}$, reaches a maximum around 3 ps and subsequently decays, disappearing after 500 ps. c) Gain spectra at 3 ps (the time delay of maximum absorption bleach) for various fluences. For high photon fluence, gain with a large bandwidth is observed. d) Time dependent nonlinear absorption plotted at the just above the gain maximum (dotted line in c. at $1.58 \mathrm{eV}$ ) for various fluences. At this energy the two highest fluences exhibit gain over a period of $200 \mathrm{ps}$. The inset shows the minimum absorption vs. fluence. The red solid line is a $3^{\text {rd }}$ order polynomial fit that serves to guide the eye. A measured gain threshold of $\sim 16 \mu \mathrm{J} / \mathrm{cm}^{2}$, and an optical gain coefficient of $3200 \pm 830 \mathrm{~cm}^{-1}$ is demonstrated at $1.58 \mathrm{eV}$.

ToC figure 


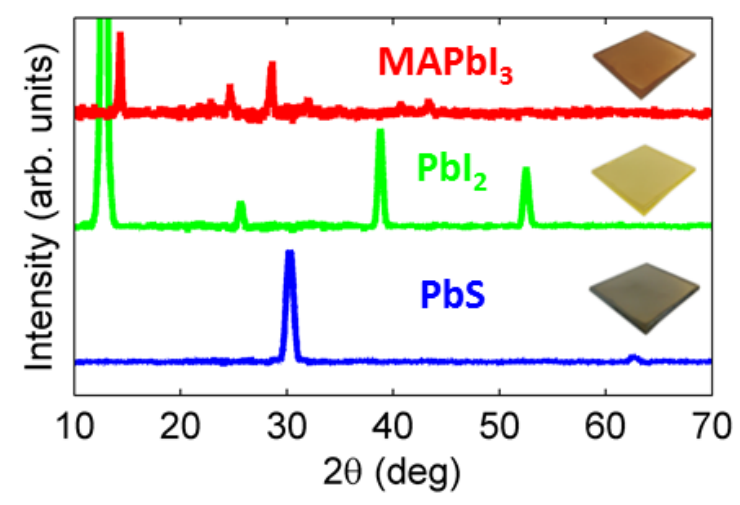

